\title{
Células Granulares Eosinofílicas / Células Mast (CGE / MC) y su relación con los efectos de herbicidas: Caso del Glifosato y surfactantes acompañantes en peces
}

\author{
Eosinophlic granular cells / Mast cells and their relation with \\ the effects of herbicides: Case of glyphosate and accompaning \\ surfactants on fish
}
Células de grânulos eosinofílicos / Mast células (CGE / MC)
e sua relação com os efeitos de herbicidas: Caso glifosato
e surfactantes que acompanha em peixes.

Jeraldyn Argüello-Rangel ${ }^{1}$; Pedro A. Triana-García ${ }^{1}$; Pedro R. Eslava-Mocha ${ }^{2}$

1 MVZ, Unillanos;

2 MV, MSc, Estudiante de Doctorado en Ciencias Agrarias Unillanos

Email: pedro.eslava@unillanos.edu.co

Recibido: diciembre 12 de 2014

Aprobado: junio 4 de 2015

\begin{abstract}
Resumen
Los Mastocitos, Células Granulares Eosinofílicas (CGE) o células Mast de los peces (MC) pertenecientes al sistema inmune, han sido relacionadas en diferentes tipos de respuestas fisiológicas y patológicas en peces. Recientemente, se ha incrementado el interés científico relacionado con su participación en reacciones ante contaminantes acuáticos, así mismo, frente a agentes infecciosos y últimamente como modelos de peces para estudiar enfermedades que involucran desordenes alérgicos y alteraciones neurodegenerativas en los seres humanos. Numerosos trabajos en varias especies de teleósteos han demostrado que los comportamientos de CGE / MC son relevantes para estudiar mecanismos anti-infecciosos. Así mismo, se ha estudiado su respuesta ante la exposición a contaminantes tales como los herbicidas, que pueden interferir con el sistema nervioso y el olfato de los peces. Se muestran datos de trabajos sobre mastocitos de peces y se sugiere la importancia de estudiarlas también como biomarcador ante contaminantes. En esta revisión se enfatiza su participación en las respuestas de diferentes órganos y tejidos ante la exposición a herbicidas como el glifosato y los surfactantes acompañantes en las mezclas asperjadas, su morfología, su papel fisiológico y patológico, y sobre algunas posibles formas de estudiarlas en el sistema nervioso, especialmente, frente a exposiciones subletales a pesticidas.
\end{abstract}

Palabras clave: Mastocitos, POEA, Roundup $®$, toxicidad, patología toxicológica de peces, inmunohistoquímica, telencéfalo.

\begin{abstract}
The mast cells of the immune system, which in fish are referred to as eosinophilic granule cells (EGC), have been related to different types of physiological and pathological responses in fish. Recently, there is increased scientific interest related to
\end{abstract}


these cells' participation in reactions to water pollution, against infectious agents, and lastly, their use as models for studying the allergic and neurodegenerative disorders in humans. Numerous studies in various species of teleost have shown that the behavior of CGE/MC are relevant for studying anti-infective mechanisms. Also, researchers have studied their response to exposure to pollutants, such as herbicides, which can interfere with the nervous and olifactory systems of fish. This review of the literature shows data from various studies on mast cells of fish which suggest the importance of them being a good biomarker to contaminants. This review emphasizes the participation in the responses of different organs and tissues from exposure to herbicides such as glyphosate and accompanying surfactants in the mixtures that are sprayed, and the morphological, physiological, and pathological role, and some possible ways to study them as well in the nervous system, especially compared to sublethal exposures to pesticides.

Keywords: Mast Cell, POEA, Roundup ${ }^{\circledR}$, toxicity, toxicological fish pathology, immunohistochemistry, telencephalon.

\section{Resumo}

Os mastócitos (MC), células de grânulos de eosinófilos (CGE) ou peixe mastócitos pertencem ao sistema imunitário têm sido relacionadas com diferentes tipos de respostas fisiológicas e patológicas em peixes. Recentemente, tem aumentado o interesse científico relacionado com a sua participação nas reacções à poluição da água, também, contra agentes infecciosos e ultimamente como modelos para estudar doenças dos peixes envolvendo doenças alérgicas e doenças neurodegenerativas em humanos. Numerosos estudos em diversas espécies de teleósteos mostraram que o comportamento de CGE / MC são relevantes para o estudo de mecanismos de anti-infecciosos. Além disso, nós estudamos a sua resposta à exposição a poluentes, tais como herbicidas, que podem interferir com o sistema nervoso e o cheiro de peixe. Dados de emprego em mastócitos e peixe é também a estudar a importância de biomarcador sugeriu aos contaminantes. Nesta revisão sua participação nas respostas dos diferentes órgãos e tecidos da exposição a herbicidas, como companheiros de glifosato e surfactantes polvilhado em misturas, morfologia, papel fisiológico e patológico é enfatizada, e algumas maneiras possíveis para estudá-los no sistema nervoso, especialmente em comparação com as exposições subletais a pesticidas.

Palavras-chave: Mastro, POEA, Roundup ${ }^{\circledR}$, toxicidade, toxicológicas patologia de peixes, imuno-histoquímica, telencephalon.

\section{Introducción}

Tanto a nivel global como en Colombia, los herbicidas representan la mayor proporción de los pesticidas utilizados en la agricultura. El uso de los plaguicidas en el mundo se estima alrededor de 2,4 mil millones de $\mathrm{kg}$, de los cuales la mayor proporción, un 40\%, cerca de 950 millones de kg son herbicidas (EPA, 2012). Los herbicidas se utilizan en la agricultura, la silvicultura, y, manejo de zonas verdes urbanas, pero los usos agrícolas dominan el mercado. Con el número y variedad de cultivos que han sido modificados genéticamente (OGM) para ser tolerantes a herbicidas, el uso de estos productos aumentará en el futuro. Hasta ahora el herbicida más utilizado en cultivos OGM ha sido el glifosato (GP), (Duke and Powles, 2008), aunque otros cultivos se han modificado para la resistencia a otras clases de pesticidas como los imitadores de la auxina, 2,4-D, y productos conexos. El aumento del uso sobre los cultivos transgénicos se traducirá en una mayor entrada de herbicidas a los agro-ecosistemas con aumentos concomitantes y potenciales vertimientos al ambiente, especialmente sobre los cuerpos de agua en particular, con efectos sobre los organismos acuáticos (Mortensen et al., 2012). El uso de herbicidas en la agricultura puede resultar en su presencia en varias matrices ambienta- les, incluidos los ecosistemas acuáticos, donde los agroquímicos pueden llegar fácilmente a las aguas superficiales de campos agrícolas por escorrentía y lixiviación (Borggaard and Gimsing, 2008). El ingrediente glifosato (GP), $\mathrm{N}$-(fosfonometil)-glicina es un herbicida de amplio espectro, no selectivo de postemergencia que inhibe la ruta del ácido shikímico y afecta a la biosíntesis de aminoácidos aromáticos: fenilalanina, tirosina y triptófano (Solomon et al., 2013). El uso a gran escala de GP se explica en parte por su aplicación a variedades de plantas genéticamente modificadas (Williams et al., 2000) que tienen una gen que confiere resistencia a la molécula de herbicida, evitando el bloqueo de la acción en la enzima EPSPS (La EPSPS cataliza la reacción entre el shikimato-3-fosfato (S3P) y el fosfoenolpiruvato (PEP) para formar 5-enolpiruvil shikimato-3-fosfato (EPSP). Además, las diferentes formulaciones de GP son utilizados en las prácticas agroindustriales como la maduración de caña de azúcar, silvícolas y en ambientes urbanos (Borggaard and Gimsing, 2008). Roundup ${ }^{\circledR}$ está registrado en más de 100 países y esta disponibles bajo diferentes marcas. Entre estas formulaciones podemos destacar Roundup Transorb (RT), que fue desarrollado para su uso durante los períodos de lluvia debido al hecho de que su absorción por la planta tarda sólo 1 h, mientras 
que las otras formulaciones de Roundup ${ }^{\circledR}$ necesitan por lo menos 4 horas para ser absorbidos (Rodriguez and Almeida, 2005). RT contiene glifosato $(480 \mathrm{~g} / \mathrm{L}-1)$ e ingredientes inertes que se registran como una mezcla de tenso-activos que contiene $15 \%$ de polioxietilamina (POEA) (Howe et al., 2004). Este agroquímico se clasifica como moderadamente tóxico (Clase III), de acuerdo con la clasificación toxicológica, y peligrosos para el medio ambiente, según Clasificación del riesgo Potencial (Monsanto, 2010). Según la Organización Mundial de la Salud, la toxicidad de glifosato es baja (OMS, 1994). Sin embargo, los productos basados en GP son generalmente más tóxicos para los peces (Amarante Junior et al., 2002, Peixoto, 2005). Las preparaciones comerciales de Glifosato se han diversificado con diferentes concentraciones en varios países, tales como: Roundup ${ }^{\circledR}$ WeatherMax, Roundup ${ }^{\circledR}$ PowerMAX ${ }^{\top M}$, Roundup ${ }^{\circledR}$ Active, Roundup ${ }^{\circledR}$ Transorb; Roundup Ultra ${ }^{\circledR}$, y Roundup UltraMax ${ }^{\mathrm{TM}}$ y se utilizan sobre cultivos genéticamente modificados denominados Roundup Ready®. Los productos con GP de Monsanto están registrados en más de 130 países para el control de arvenses o malezas en gran diversidad de cultivos, especialmente, soya, maíz y algodón (Solomon et al., 2013). Adicionalmente, en Colombia el GP es usado como herbicida de amplio espectro en prácticas agrícolas y se ha venido utilizando bajo la denominación Roundup Ultra ${ }^{\circledR}$ (variedad del Roundup ${ }^{\circledR}$ que varía ligeramente en la concentración de sus componentes) en las prácticas de erradicación química de los cultivos de coca y amapola en una mezcla a la que se le adiciona el surfactante Cosmoflux ${ }^{\circledR} 411 \mathrm{~F}$ (Nivia, 2001). Estas mezclas de herbicidas están entre las más utilizadas a nivel mundial y se carece de la información completa sobre la composición del producto que incluye "elementos inertes" de características desconocidas que no se describen en la etiqueta. Entre los elementos inertes están los surfactantes, que son agentes modificadores de la tensión superficial que se añaden a las formulaciones para aumentar la penetración a través de la cutícula y en los tejidos de plantas. Sin embargo, algunos tensoactivos particulares de fórmulas comerciales no se encuentran especificados en la etiqueta, siendo según (Vigil et al., 2004) seleccionados entre compuestos pertenecientes a una lista de familias químicas, por ejemplo, alkanolamidas, alquil arilsulfonatos, aminas y amidas sulfonatadas, alquilfenoles etoxilados, ácidos grasos etoxilados, alcoholes sulfatados y etoxilados, derivados del sorbitol, ésteres de fosfato, entre muchas otras. En muchos casos, en las preparaciones comerciales de uso agrícola la toxicidad de tales tenso-activos puede ser mayor que el GP para los organismos acuáticos (Solomon et al., 2013). Estas formulaciones son rápidamente disipadas en aguas superficiales, en donde el GP sufre una biodegradación a AMPA (ácido aminometilfosfonico), el cual tiene la misma toxicidad que el glifosato (Giesy et al., 2000, Monheit, 2003), posteriormente es degrado a metilamina y finalmente a dióxido de carbono $\left(\mathrm{CO}_{2}\right)$ y amonio $\left(\mathrm{NH}_{3}\right)$ (Evrard et al., 2010, Glusczak et al., 2007). El uso de mezclas con GP genera preocupación con respecto a la contaminación de los ecosistemas acuáticos, ya que se ha demostrado que el GP y sus subproductos son más móviles y persistentes en estos ambientes (Kolpin et al., 2006). En la naturaleza, no necesariamente la exposición a tóxicos produce la muerte de los animales, en muchos casos, los organismos intentan sobreponerse a las exposiciones mediante diversos "ajustes" metabólicos o fisiológicos, mediados por mecanismos tales como el estrés u otras respuestas adaptativas que sin embargo, pueden tener consecuencias sobre las poblaciones. Los herbicidas pueden generar efectos subletales sobre los peces, que se expresan en respuestas anómalas relacionadas con el desarrollo, el crecimiento, la reproducción y comportamiento (van der Oost et al., 2003). A raíz de la exposición a un tóxico se desata una reacción que involucra la puesta en marcha de una cascada bioquímica, celular y metabólica para contrarrestar los efectos nocivos de este. Esto puede suceder, a través de la depuración del toxico o por la transformación en moléculas de menor bioactividad (Langiano and Martinez, 2008, Cazenave et al., 2009).

El sistema nervioso central y las vías de acceso a través de órganos de los sentidos, entre ellos el olfato, transmiten información ambiental fundamental para los peces. Las actividades vitales, como el apareamiento, la localización de alimentos, discriminación de familiares y evasión de depredadores son comportamientos que pueden verse afectados o perdidos como consecuencia de la exposición a contaminantes tóxicos en las aguas. Los estudios de olfato en teleósteos se han centrado en las respuestas de comportamiento como por ejemplo de evasión a los contaminantes (Tierney et al., 2007). Más recientemente, ha habido cambios en la comprensión de los mecanismos subyacentes y la importancia funcional de contaminantes a través del olfato en peces. Esto incluye considerar contaminantes que afectan el sistema olfativo y, por extensión, la respuesta fisiológica, o los procesos de comportamiento que comprenden una respuesta normal a estímulos naturales como por ejemplo, el crecimiento, la reproducción o la liberación de feromonas. Numerosos trabajos en varias especies han demostrado que es 
ecológicamente relevante la exposición a contaminantes comunes tales como metales y pesticidas que pueden interferir con el sistema nervioso y el olfato en los peces y alterar por esa vía procesos en el ciclo de vida que determinan la supervivencia individual y el éxito reproductivo (Tierney et al., 2010, Tierney et al., 2007, Solomon et al., 2013). Se han realizado experimentos con herbicidas en los que las Células granulares eosinofilicas / mastocitos de los peces CGE/MC están involucradas en la respuesta tanto en el telencéfalo como de vías olfatorias (Ramirez-Duarte et al., 2008, Castañeda, 2012) y por consiguiente, se postulan como marcadores de exposición, de tal modo que a través de estudios histopatológicos e inmunohistoquímicos sea posible considerarlas como variable a monitorear en investigaciones que midan el impacto de diferentes tóxicos sobre peces teleósteos en el medio acuático. Se ha identificado además, que hay un aumento en el número de CGE/MC en diversos tejidos y órganos de teleósteos vinculado a diversas condiciones generadoras de estrés, como la exposición a metales tóxicos (cadmio, cobre, plomo y mercurio) y la exposición a herbicidas o agentes tóxicos (Ramirez-Duarte et al., 2008, Lauriano et al., 2012). Por ello, se considera que esta población celular podría usarse como biomarcador, teniendo en cuenta que el término hace referencia a los cambios celulares, bioquímicos, moleculares, o fisiológicos que son medidos en células, fluidos, tejidos u órganos dentro de un organismo y que indican la exposición o efecto de un xenobiótico. Especialmente en circunstancias ambientales reales aún bajo exposiciones sub-letales, las alteraciones histopatológicas pueden modificar significativamente la función de tejidos y células, señalando así los efectos de la exposición ante agentes tóxicos (van der Oost et al., 2003). Dichos cambios dependerán de la capacidad del organismo para reparar la injuria, la naturaleza y la severidad de la contaminación y el tiempo de exposición (Lourenço et al., 2011). Algunos estudios realizados con juveniles de cachama blanca (Piaractus brachypomus) concluyen que el Roundup ${ }^{\circledR}$ genera alteraciones patológicas, en las branquias, hígado, riñones, piel y cerebro; en el caso del cerebro específicamente en los bulbo olfativos y el telencéfalo se encontraron CGE/ MC que pueden estar asociadas con la activación o aceleración de los procesos apoptóticos y otras respuestas de las neuronas y demás componentes del tejido nervioso (Ramirez-Duarte et al., 2008).

En esta revisión se hará énfasis en el papel de las células granulares eosinofilicas CGE/MC de los peces, y su participación en las respuestas de diferentes órganos y tejidos ante la exposición a herbicidas como el glifosato, su morfología, su papel fisiológico, y sobre algunas formas de estudiarlas en el sistema nervioso en respuestas fisiopatológicas, especialmente, frente a exposiciones subletales a pesticidas.

\section{Respuestas agudas y crónicas de peces ante las fórmulas comerciales de herbicidas con base en Glifosato (GP)}

Existen muchas aproximaciones metodológicas para estudiar efectos de contaminantes ambientales como los herbicidas en peces. Según (Ahmad et al., 2000) estudios del estrés oxidativo y parámetros bioquímicos, así como la histopatología, son biomarcadores útiles para la evaluación del riesgo ambiental. La combinación de parámetros de estrés oxidativo, enzimas hepáticas y de histopatología son importantes para evidenciar respuestas en los órganos internos; mientras que las medidas de estrés oxidativo son biomarcadores de la exposición, las lesiones histopatológicas y el estudio de enzimas hepáticas son biomarcadores de efecto (Ferreira et al., 2010). Se han registrado efectos, tanto del glifosato como de las diferentes formulaciones y las sustancias aditivas que lo acompañan, en diferentes especies de peces (Kelly et al., 2010, Langiano and Martinez, 2008, Neskovic et al., 1996, Shiogiri et al., 2012, Wang et al., 1994); Wang et al., 1994), especialmente salmónidos (Folmar et al., 1979, Hildebrand et al., 1982, Mitchell et al., 1987, Peterson and Hulting, 2004, Antón et al., 1994). En relación con peces neotropicales de agua dulce el Roundup ${ }^{\circledR}$, que contiene el POEA en su formulación, se ha determinado más tóxico para los organismos acuáticos que el glifosato (Giesy et al., 2000, Tsui et al., 2005). Los estudios toxicológicos han demostrado que el uso crónico de Roundup $\circledast$ es potencialmente nocivo para los organismos no blanco (Giesy et al., 2000, Relyea, 2005) y los peces que viven en aguas poco profundas (Albinati et al., 2007). Se han reportado diversos tipos de alteraciones en los peces expuestos a glifosato, desde alteraciones en el genoma (genotoxicidad), neurotoxicidad, hepatotoxicidad, desequilibrios iónicos y lesiones necróticas en diversos órganos.

\section{Genotoxicidad}

Varios estudios que utilizan diferentes pruebas (in vivo e in vitro) han informado de alta genotoxicidad del GP (Sivikova and Dianovsky, 2006, Sparling et al., 2006, Cavas and Konen, 2007, Alvarez-Moya et al., 2011, Guilherme et al., 2012). La genotoxicidad observada está relacionada con el organismo de prueba utilizado (Zúñiga, 2001), por ejemplo, las plantas (Dimitrov et al., 2006, Alvarez-Moya et al., 2011, Truta et al., 2011), los peces (Cavas and Konen, 2007) y las células hu- 
manas (De Roos et al., 2005, Bolognesi et al., 2009) son muy sensibles al GP. Teniendo en cuenta la importancia de los enfoques que implican los efectos genotóxicos de los contaminantes sobre los organismos acuáticos, así como la escasez de información con respecto a estos daños genéticos producido por RT y el GP en peces, se han diseñado estudios para evaluar el daño del ADN en peces expuestos a GP y RT; uno de ellos es el ensayo cometa, ensayo conocido como SCGE (ensayo de electroforesis en gel de célula única) siendo uno de los más utilizados (Langiano and Martinez, 2008). (Alvarez-Moya et al., 2014) mediante un ensayo cometa, demostró genotoxicidad de isopropilamina de glifosato $(0,7,7,70$ y $700 \mu \mathrm{M})$ en linfocitos humanos y en eritrocitos de Oreochromis niloticus in vitro e in vivo. Estos resultados indican que el GP es genotóxico en las células y los organismos estudiados

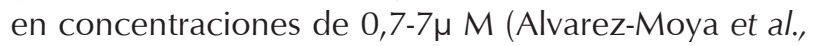
2014). La exposición al Roundup ${ }^{\circledR}$ también ha sido asociada con lesiones al ADN en varias especies de peces y al ser humano (Cavas and Konen, 2007, Paz-yMino et al., 2002) y con alteraciones en el ciclo celular (Marc et al., 2004b). Un trabajo reciente (Moreno et al., 2014) indica que tanto el GP como el Roundup ${ }^{\circledR}$ Transorb (RT) causan daños a la molécula de ADN de Prochilodus lineatus corroborando que el ingrediente activo puede contribuir a la genotoxicidad de la formula, y que ambos actúan con más intensidad en eritrocitos que en células branquiales. En conjunto, estos resultados revelaron que tanto el mismo GP como el producto formulado RT son genotóxicos para las células branquiales y los eritrocitos de $P$. lineatus, lo que sugiere que su uso debe ser monitoreado cuidadosamente teniendo en cuenta su impacto potencial en biota acuática tropical (Moreno et al., 2014) .

\section{Alteraciones Morfo-funcionales}

En peces se han observado diversas alteraciones de la morfología y la función celular, tales como, desequilibrio iónico, respuestas de estrés y alteraciones histopatológicas en hígado, eritrocitos y células branquiales expuestos a diversas formulaciones de GP (Cavalcante et al., 2008, Langiano and Martinez, 2008). Por ejemplo, la exposición a Roundup $®$ Transorb cambió la actividad de las enzimas antioxidantes e indujo la inhibición de la acetilcolinesterasa (Modesto and Martinez, 2010b, Modesto and Martinez, 2010a). en cuanto a respuestas crónicas y agudas, se ha observado que la exposición a largo plazo al Roundup provoca alteraciones metabólicas en Leporinus obtusidens. Las respuestas de los peces permiten concluir que al menos un estado de aclimatación parcial se obtuvo después de exposiciones prolongadas a Roundup, debido a la alta tasa de supervivencia. Sin embargo, el crecimiento se redujo, y varios parámetros metabólicos y hematológicos se alteraron, lo que indica toxicidad del Roundup (Salbego et al., 2010). Por otro lado, en cuanto a efectos agudos, se considera que la toxicidad del Roundup (particularmente del glifosato) en animales es baja de acuerdo con la Organización Mundial de la Salud, pero su amplio uso puede causar problemas ambientales con impacto negativo sobre la fauna silvestre, especialmente en el ambiente acuático, donde pueden persistir químicos por mucho tiempo. (Lushchak et al., 2009) estudiaron los efectos de Roundup mediante marcadores de estrés oxidativo y defensa antioxidante en Carassius auratus, encontrando que Roundup en general suprimió las actividades de las enzimas superóxido dismutasa (SOD), glutatión S-transferasa (GST), la glutatión reductasa y deshidrogenasa de glucosa-6-fosfato en tejidos de los peces expuestos. Se considera como un primer estudio que demuestra una respuesta sistemática por los sistemas antioxidantes de los peces a la exposición Roundup ${ }^{\circledR}$ mostrando que concentraciones relativamente bajas de herbicidas pueden causar efectos adversos en el estado antioxidante en los peces. Se ha demoestrado que el Roundup ${ }^{\circledR}$ tiene efectos sobre el metabolismo de los animales que pueden ser dañinos, especialmente si la exposición es prolongada (Lushchak et al., 2009), alterando la expresión génica que pueden conllevar a una alteración en el balance energético y la síntesis de proteínas (Marchand et al., 2006). En cuanto a alteraciones morfológicas, varios autores han reportado el desarrollo de lesiones necróticas y proliferativas, así como el desarrollo de aneurismas e infiltrados leucocitarios en las branquias; lesiones hepáticas consistentes en cambios degenerativos, vacuolizaciones lipídicas y gotas hialinas citoplasmáticas en los hepatocitos de peces expuestos a formulaciones comerciales de GP en exposiciones agudas (Neskovic et al., 1996, Szarek et al., 2000, Jiraungkoorskula et al., 2002, Jiraungkoorskul et al., 2003, Ramirez-Duarte et al., 2008). Así mismo, se han reportado lesiones en el telencéfalo de la cachama blanca en exposiciones agudas al Roundup ${ }^{\circledR}$ (Ramirez-Duarte et al., 2008) y a la mezcla Roundup ${ }^{\circledR}$ más Cosmoflux ${ }^{\circledR}$ 411F (Ramírez D et al., 2009). Se han observado alteraciones histopatológicas en el hígado después de exposiciones agudas y / o crónicas a Roundup ${ }^{\circledR}$ en Oreochromis niloticus (Jiraungkoorskul et al., 2003, Jiraungkoorskula et al., 2002) y Prochilodus lineatus (Langiano and Martinez, 2008) y cambios ultraestructurales en los hepatocitos de Cyprinus carpio (Szarek et al., 2000). En Piaractus mesopotamicus las lesiones hepáticas se clasificaron como moderadas a severas incluyendo vacuolizaciones del citoplasma, acumulación de lípidos, alteración 
de las membranas celular y nuclear y depleción de los depósitos de glucógeno sugiriendo alteraciones en la función hepática (Shiogiri et al., 2012). La exposición a glifosato y surfactantes induce lesiones en las membranas celulares (disminución de surcos superficiales) de células epiteliales así como daños asociados a desorganización del citoesqueleto (Elie-Caille et al., 2010). Estos daños de membrana se relacionan con liberación de componentes intracelulares así como pérdida de la regulación iónica. Por otra parte, (Elie-Caille et al., 2010) demostraron que las células expuestas a glifosato evidencian cambios característicos de procesos apoptóticos. Estos fenómenos pueden derivarse de la lesión mitocondrial ya descritas ante la exposición a estas sustancias (Szarek et al., 2000).

\section{Toxicidad olfativa}

Un aspecto de particular importancia en relación con efectos subletales de los pesticidas es la capacidad de alterar respuestas olfativas: la respuesta de los peces a estímulos olfativos ha sido el objeto de una serie de trabajos que a menudo se realizaron en relación con los comportamientos de alimentación; la mayoría de estos estudios se han centrado en efectos de insecticidas (Jarrard et al., 2004) que son generalmente más tóxico para los peces y con frecuencia afectan el sistema nervioso directamente. El olfato transmite la información ambiental fundamental para los peces, las actividades de apoyo, como el apareamiento, la localización de alimentos y evasión de depredadores hacen parte de respuestas mediadas por estímulos olfativos. La toxicidad del sistema olfativo, representa una de las vías por las que los productos químicos tóxicos en los hábitats acuáticos pueden contribuir cada vez más a las disminuciones ecológicamente importantes en poblaciones de peces. Según (Tierney et al., 2010) a pesar de nuestro entendimiento emergente de las amenazas que la contaminación representa para la comunicación química en el medio acuático, muchos desafíos de investigación permanecen. Estos incluyen: (1) la determinación de los mecanismos específicos de la toxicidad en el epitelio sensorial olfativo de peces; (2) la comprensión de los impactos del complejo de mezclas químicas; (3) la capacidad para evaluar la toxicidad olfativa en los peces in situ; (4) el impacto de las toxinas en comportamientos-olfativos que todavía no se entienden bien para muchas especies de peces; y (5) las conexiones entre los efectos subletales sobre peces individuales y la viabilidad a largo plazo de las poblaciones silvestres (Tierney et al., 2010). A través de estudios a lo largo de los niveles de la organización olfativa el tema recurrente es que una variedad de pesticidas, agentes tenso-activos, metales e hidrocarburos alteran la función y estructura olfativa de las neuronas sensoriales y las respuestas conductuales de orden superior que apoyan. Los estudios de toxicidad futuros se beneficiarían mediante la vinculación de efectos de la exposición al crecimiento, la reproducción o el reclutamiento, que juntos representan niveles de supervivencia correspondiente a la población. Relacionando la importancia de una disminución en la respuesta de la neurona olfativa a partir de una exposición a los pesticidas a corto plazo con un impacto a nivel de población, los estudios de toxicidad olfativa deben permitir enlazar los mecanismos de la toxicidad a las respuestas de comportamiento que pueden estar relacionados con los cambios en la supervivencia, sobre todo a nivel de ecosistema. Varios estudios indican que existen umbrales entre la respuesta neurológica y fisiológica y las respuestas de comportamiento. Además, otros efectos tóxicos, tales como los independientes del olfato y posiblemente con mecanismos de acción desconocidos, deben tenerse en cuenta al determinar toxicidad en el organismo. En última instancia, tendrá que ser revisada la reglamentación sobre los niveles de contaminantes dónde se observen efectos negativos basadas en respuestas olfativas. En la actualidad, se dispone de información para indicar que el olfato en peces es sensible a los contaminantes, los cuales hacen el seguimiento de su función una buena aproximación para el mantenimiento de las poblaciones de peces en un entorno cambiante (Tierney et al., 2010). Aunque un número de estudios han reportado respuestas de comportamiento a herbicidas, la importancia de estas respuestas en la supervivencia, el crecimiento, el desarrollo y la reproducción o la sostenibilidad de las poblaciones de peces no han sido cuantificadas, salvo en un sentido especulativo o modelado. Estas conductas pueden ser adaptativas, y se pueden producir por habituación a las alteraciones del ambiente. Lo mismo probablemente cierto para las respuestas de comportamiento en otros animales a menos que sean como resultado de neurotoxicidad directa o efectos sobre el desarrollo en los mamíferos (Allen, 2010). Otra revisión sobre el tema analiza efectos subletales de herbicidas que incluyen efectos en la reproducción, el estrés, el olfato, y el comportamiento; aunque algunas de estas respuestas se han observado en los peces expuestos a herbicidas, se han observado en grandes concentraciones que serían raramente encontradas en las aguas superficiales habitadas por peces. En el caso de la conducta, no se han relacionado con las respuestas ecológicamente significativas sobre supervivencia, el crecimiento, el desarrollo, y la reproducción (Solomon et al., 2013) pero el pa- 
pel de tales sustancias en la generación de disturbios fisiológicos aún dista mucho de ser esclarecida. Se sabe que los mayores efectos observados con Roundup ${ }^{\circledR}$ se relacionan con los «ingredientes inertes» de la formulación, tales como los surfactantes, muchos de estos productos químicos son conocidos por ser sustancias tóxicas al olfato de peces (Sutterlin et al., 1971). Como se ha descrito arriba, pocos estudios se han llevado a cabo con herbicidas, se han efectuado mediciones electrofisiológicas a respuestas olfativas en la trucha arco iris expuestos a atrazina y una formulación de sal de GP que contienen glifosato de isopropilamina (IPA), y un agente tensoactivo POEA (Tierney et al., 2007). La atrazina no provocó ninguna respuesta olfativa en concentraciones de 10 y 100 mg / L y se observaron con 100 y 1,000 mg de GP/ IPA. Las respuestas olfativas no fueron fuertemente $O$ proporcionalmente correspondientes en relación con las respuestas de comportamiento, sin embargo, en cuanto a las respuestas de comportamiento, no está claro qué efecto de la percepción de una sustancia química o la interferencia de la sustancia química con la percepción de otras señales ambientales y de alimentación tiene en la supervivencia, el crecimiento, el desarrollo, o reproducción (Tierney et al., 2010).

\section{Neurotoxicidad}

Algunos de los efectos relacionados con neuro toxicidad tienen que ver con alteraciones en la función de la enzima Acetilcolinesterasa (AChE). Según (Salbego et al., 2010) la actividad AChE cerebral y los parámetros hematológicos pueden ser útiles como indicadores de exposición a largo plazo a formulaciones comerciales que contienen GP. Por ejemplo, mediante un experimento de exposición crónica en Leporinus obtusidens (Piava) sometidos a diferentes concentraciones de Roundup, una formulación herbicida comercial que contiene GP $(0,1$, o $5 \mathrm{mg}$ L-1), durante 90 días se demostró que la actividad AChE del cerebro se redujo significativamente en los peces expuestos a $5 \mathrm{mg} \mathrm{L}-1$ Roundup, mientras que la actividad AChE de musculo no fue alterada. Se observaron alteraciones como disminución del glucógeno hepático, reducción de niveles de glucosa, lactato, proteínas hepáticas y musculares en los peces expuestos (Salbego et al., 2010). La mayoría de efectos observados se producen a concentraciones ambientales relevantes, $y$, en resumen, los resultados muestran que Roundup afecta a la actividad AChE del cerebro, así como alteraciones metabólica y alteraciones de parámetros hematológicos de piavas.

\section{Aspectos morfológicos y funcionales de las células granulares eosinofílicas / Células Mast de los peces (CGE/MC)}

Los mastocitos o células mast (MC) son células importantes como iniciadoras y efectoras de la inmunidad innata y en la regulación de la respuesta inmune adaptativa; se han descrito en todas las clases de vertebrados y parecen ser morfológica y funcionalmente similares; sin embargo, desde los primeros estudios se encontraron diferencias en peces y anfibios en relación con el contenido de sus gránulos y las propiedades histoquímicas. Según lo descrito por Paul Ehrlich en 1878, los MC son células granulares del tejido conjuntivo de los vertebrados, que se tiñen metacromáticamente con anilina y se localizan con muy alta frecuencia alrededor de los vasos sanguíneos en el tejido conectivo laxo (Vallejo and Ellis, 1989, Kunder et al., 2011). En teleósteos las MC se han descrito en varias especies (Mulero et al., 2007). Las características de tinción y contenido de los gránulos pueden variar entre especies, pero una ubicación predominantemente perivascular es constante (Reite, 1998). Las MC se degranulan (respuesta a corto plazo) o proliferan (respuesta a largo plazo) ante agentes patógenos o irritantes (Powell et al., 1993, Vallejo and Ellis, 1989). El término de Células Granulares Eosinofilicas (CGE) / Mast (MC) fue usado por (Roberts et al., 1972) para designar a unas células mononucleares que contenían gránulos eosinofílicos y que estaban distribuidas en el tejido conectivo de diversos teleósteos (Alvarez-Pellitero, 2008). Se ha hallado que dichas células liberan una amplia gama de compuestos bioactivos, como la heparina, neuropéptidos, y proteasas neutras (Baccari et al., 2011), péptidos antimicrobiales (PAM) como la lisozima, piscidinas y pleurocidinas, que son abundantes en la mucosa de los peces, y reaccionan fuertemente a la inflamación a través de la migración y la liberación de gránulos. Contienen además, componentes comunes con los gránulos de las células mast de los mamíferos, e.g. fosfatasas alcalinas y ácidas, arilsulfatasa, 5-nucleotidasa, y 5-HT (serotonina) (Reite and Evensen, 2006, Dezfuli et al., 2011, Buonocore et al., 2012, Rombout et al., 2011). La producción de CGE/MC en peces adultos tiene lugar en el riñón craneal y el bazo, pues representan los sitios de mayor hematopoyesis (Da'as et al., 2012, Baccari et al., 2011, Prykhozhij and Berman, 2014), aunque dicha propiedad también es posible en otros órganos e.g. tejido linfoide asociado a mucosas, y timo (Press and Evensen, 1999). (Holland and Rowley, 1998), establecían que el incremento de CGEs/Mast en tejido branquial de trucha arcoíris (Oncorhynchus mykiss) se daba presumiblemente a la diferenciación de precursores celulares en las branquias. Se ha demostrado por tanto, que los precursores no granulados de células 
granulares residen en el tejido y siempre que hay la disponibilidad de los factores necesarios, se convierten en CGE/MC (Reite and Evensen, 2006), en otras palabras, las células se forman (Matsuyama and lida, 1999) en órganos hematopoyéticos y posteriormente migran al tejido blanco, donde maduran y adquieren sus diferentes funciones (Da'as et al., 2012, Sfacteria et al., 2015). En los peces se encuentran con más frecuencia en la piel (Blackstock and Pickering, 1980, Zaccone, 1982, Gómez et al., 2013), así como en el tejido conectivo y epitelial del tracto digestivo y branquias (Reite, 1998, Matsuyama and lida, 1999, Jordanova et al., 2007, Leknes, 2007, Alvarez-Pellitero, 2008, Garg et al., 2010, Dezfuli et al., 2011, Dezfuli et al., 2013, Gomez et al., 2013); en sistema urinario, reproductivo, bazo, riñones, y vejiga natatoria. (Hellberg et al., 2013) las identificaron mayormente en el intestino de pez lobo (Anarhichas lupus L.), y al compararlas con trucha arcoíris, se evidenció que solo se asociaban estrechamente a vasos linfáticos en los primeros; además, en trucha arcoíris los gránulos de las CGE/MC tenían una estructura globular intacta, mientras que en pez lobo observaban vacuolas vacías. Las CGE/MC se han identificado también en otro órganos como el hígado (Jordanova et al., 2007) quienes hallaron que estas células estaban distribuidas regularmente en el hígado de trucha de Ohrid (Salmo letnica) lo cual atribuían a la conexión de la especie con las condiciones de su hábitat, y la necesidad de adaptarse a lo largo de su proceso evolutivo para constituirse como parte de la defensa del huésped. Se cree que la propiedad metacromática de las CGE/MC es altamente dependiente de la naturaleza del fijador usado y del subsecuente método de tinción empleado. Se ha reportado además, el uso de técnicas de inmunohistoquímica indirecta siendo la técnica de inmunocomplejo peroxidasa-anti-peroxidasa usada habitualmente para identificar los productos de degranulación de las CGE/MC de los peces, así como el método Complejo Avidina-Biotina ( $A B C)$,la reacción peroxidasa y los ensayos de inmunoabsorbancia (Baccari et al., 2011). Las técnicas de cultivo in vitro de poblaciones homogéneas de CGE/MC también han cobrado relevancia para estudiar la fisiología de las mismas a través de cultivos explante de órganos. Una señal histoquímica ampliamente aceptada de las CGEs/Mast como ya se ha mencionado, es la metacromasia expresada por sus gránulos con tinciones de anilina básica o una tiazina como azul de toluidina (Dobson et al., 2008, Baccari et al., 2011). Esta característica se explica por la presencia de glucosaminoglicanos sulfatados como la heparina, que le confieren esta capacidad y por consiguiente permite distinguirlas de otro tipo de células morfológicamente parecidas (Baccari et al., 2011). En pez cebra (Danio rerio) el grupo de CGE/MC comparte con las denominadas células rodlet y eosinófilos la coloración eosinofílica con HE y el ser PAS-positivas. Se ha evidenciado que son fácilmente distinguibles con azul de toluidina en tejidos de branquia e intestinos, además de responder a secretagogos específicos expresando c-kit, triptasa y carboxipeptidasa a5 (cpa5) (Da'as et al., 2011, Dobson et al., 2008), en tanto los lípidos solo se han observado en salmón, la fosfatasa alcalina y ácida, $\beta$-glucuronidasa, $\mathrm{N}$-acetil- $\beta$-glucosaminidasa, y actividad esterasa se ha descrito en células mast de anfibios, aves y en varios peces (Baccari et al., 2011). Se afirma que cuando las CGE/MC retienen el color rojizo, se debe a que son deprivadas de su material granular basofílico (Reite et al., 1996). Considerando la alta solubilidad de sus gránulos como la razón de los problemas para expresar metacromasia con ciertas técnicas e.g. HematoxilinaEosina (HE), el siguiente paso fue desarrollar técnicas histoquímicas más eficientes como el tratamiento con sulfato de berberina lo que resolvió la detección de la heparina en los gránulos de CGE/MC (Holland and Rowley, 1998, Reite, 1998, Reite and Evensen, 2006, Baccari et al., 2011). Reportes que usaron Hoplias malabaricus señalan que al usar métodos fluorimétricos para la cuantificación de heparina (histoquímicamente específico de heparina para un $\mathrm{pH}$ 3,5) los gránulos de las CGEs/Mast del tejido intestinal exhiben una fluorescencia amarilla después del tratamiento con sulfato de berberina sugiriendo la presencia de heparina dentro de sus componentes (Reite, 1998).

Aunque recientemente ha aumentado el uso genérico de la denominación MC en peces, hay que señalar que hay diferencias funcionales con las células descritas en mamíferos, por ejemplo, en éstos se ligan a la IgE a través de receptores específicos (Fc\&R) que involucran procesos de activación que requieren ATPasa, histamina y otros factores liberados de las mismas (Reber et al., 2012, Silver and Curley, 2013). En los peces no se ha demostrado la presencia de IgE, y la histamina solo se ha identificado en peces del orden perciformes (Mulero et al., 2007, Rombout et al., 2011). Sin embargo, se ha podido identificar, la presencia de IgM e IgD pero no hay evidencia de si son capaces de generar degranulación de las CGE/MC (Baccari et al., 2011). Según investigaciones en pez cebra (Danio rerio), las CGE/MC poseen receptores análogos de alta afinidad (FcERI) a IgE que pueden inducir estímulos, que resultan en una reproducción clásica de respuesta sistémica anafiláctica pasiva. Dicha aseveración, se fundamenta en el hallazgo de reactividad cruzada dirigida tanto contra FceRle IgE humana; si bien no hay evidencias de IgE en peces, lo que si indica este hallaz- 
go, es que la función de respuesta anticuerpo-receptor aún se conserva en las CGE/MC (Da'as et al., 2011).

Varios de los compuestos de las CGE/MC son los mismos que en mamíferos e.g. histamina, serotonina, heparina, así como hay otros de los que aunque se ha reportado su presencia en peces teleósteos, no se ha reportado que sean mediadores secundarios producidos por las CGE/MC e.g. factores de crecimiento y quimioquinas (Secombes and Cunningham, 2004, Secombes et al., 2001, Alejo and Tafalla, 2011). Específicamente, los péptidos antimicrobiales (PAM) se consideran un importante componente del sistema inmune innato (Buonocore et al., 2012, Acosta et al., 2013, Niu et al., 2013), y están ampliamente distribuidos tanto en vertebrados como invertebrados (Cuesta et al., 2011, Sperstad et al., 2011, Buonocore et al., 2012) en leucocitos y a nivel de superficies epiteliales e.g. la piel, tracto respiratorio y gastrointestinal. Se han identificado en células de moco-piel, intestino y branquias-así como en CGE/MC, neutrófilos y células rodlet (Corrales et al., 2010). De los péptidos antimicrobiales (PAM) de los peces, las piscidinas son las más ampliamente distribuidas y muestran mayor potencial y amplio espectro de actividad contra virus, bacterias, hongos y parásitos (Corrales et al., 2010, Dezfuli et al., 2011, Buonocore et al., 2012, Niu et al., 2013). (Mulero et al., 2008), reportó que las mismas solo han sido identificadas en peces del orden perciformes, mientras que se ha detectado la presencia de otros PAM en peces e.g. pleurocidinas (Douglas et al., 2001), hepcidinas (Douglas et al., 2003), dicentracinas, moronecidinas (Lauth et al., 2002, Salerno et al., 2007) y chionodracinas (Buonocore et al., 2012), así como hay otros PAM -e.g. LEAP-2 (péptido antimicrobial-2), catelicidinas, gaduscidinas 1 y 2 , epinicidina- 1 y defensinas, aun no vinculados a alguna población celular (Bao et al., 2006, Chang et al., 2006, Yin et al., 2006, Zou et al., 2007, Cuesta et al., 2011).

(Mulero et al., 2008), determinaron que las piscidinas estaban contenidas dentro de los gránulos de CGE/MC y granulocitos acidofílicos -neutrófilos- en dorada (Sparus aurata) y que estos no solo actuaban como potentes PAM en el espacio extracelular tras la activación y degranulación de las CGE/MC, sino que podrían actuar como parte del mecanismo intracelular -fagocitosis-. Estos PAM son péptidos lineales, amfipáticos, $\alpha$-hélices que típicamente conservan el $\mathrm{N}$-terminal rico en histidina (Chekmenev et al., 2006, Noga et al., 2011) y fenilalanina; entre las piscidinas identificadas se hallan la 1, 2 y 3, estas comparten una alta homología en la secuencia de aminoácidos en sus péptidos maduros, y la sustitución de aminoácidos -excepto para la piscidina 3- ha sido de glicina por histidina en la posición
17 (Silphaduang and Noga, 2001, Lauth et al., 2002). De otro lado, los PAM lineales han sido descritos también en peces del orden pleuronectiformes incluyendo Pleuronectes americanus (Sfacteria et al., 2015), Hippoglossoides platessoides (Fabricius), Hippoglossus hippoglossus L, Limanda ferruginea (Storer), y Glyptocephalus cynoglossus L (Patrzykat et al., 2003).

\section{Las CGE/ MC en las respuestas ante agentes tóxicos en peces}

Varios investigadores han propuesto que los mastocitos son "sintonizables," tanto por factores genéticos y ambientales, de tal manera que, dependiendo de las circunstancias, la célula se puede colocar fenotípicamente para expresar un amplio espectro de variaciones en los tipos, la cinética, y / o magnitud de sus funciones secretoras (Galli et al., 2005). Como se mencionó arriba, se ha demostrado dentro de las características homologas de las CGE/MC con las células mast de los mamíferos, su capacidad de inducir una respuesta vasomotora y aumento de la permeabilidad vascular por la liberación de sus gránulos, ante la exposición a bacterias patógenas, productos bacterianos, tóxicos u otros agentes puede inducir degranulación (Ellis, 1985, Vallejo and Ellis, 1989, Reite, 1996, Lauriano et al., 2012, Sfacteria et al., 2015). La información proporcionada por las investigaciones hechas en vertebrados no mamíferos, ha llevado a plantear que los mecanismos de activación de las células Mast parecen estar altamente conservados dentro de la evolución de los vertebrados por las siguientes razones: 1) El compuesto 48/80, un miembro de la familia de secretagogos de las células Mast necesario para la estimulación de la GTPasa -la cual activa la vía de transducción de señales mediada por fosfolipasa C y D-induce degranulación de las CGE/MC en peces, anfibios, aves y mamíferos (Ellis, 1985, Vallejo and Ellis, 1989, Matsuyama and lida, 1999, Matsuyama and lida, 2002, Reite and Evensen, 2006). 2) La Sustancia P, Concanavalina A (ConA), capsaicina, hidrocortisona y toxinas promueven degranulación en algunos peces teleósteos y mamíferos (Reite, 1997, Matsuyama and lida, 1999, Reite and Evensen, 2006) 3) La activación de las células Mast de mamíferos involucra CR3 (receptor C3) para liberar agentes proinflamatorios y agentes quimiotácticos para la migración de células Mast y eosinófilos; el receptor $\mathrm{C} 3$ ha sido reportado en trucha como también en un procordado, este receptor ayuda a las CGE/ MC a reconocer e internalizar bacterias opsonizadas (Baccari et al., 2011), 4) En teleósteos como pez cebra (Danio rerio), se ha demostrado la expresión y actividad de receptores tipoToll (TLR) y están funcionalmente involucrados con las CGE/MC, soportado por 
reportes de una respuesta génica de diferenciación mieloide primaria -MyD88, una proteína adaptadora en la vía de transducción de señales de receptores TLR-(Da'as et al., 2011) y la degranulación de CGE/ MC luego de la exposición a toxinas de Aeromonas salmonicida (Mutoloki et al., 2006, Da'as et al., 2011) y 5) tanto en mamíferos como, peces óseos y sapos, se liberan neuroquinas desde las fibras nerviosas que pueden activar las MC para liberar mediadores químicos (Baccari et al., 2011). Desde mediados del siglo XX se desarrollaron estudios encaminados a analizar la función de las CGE/MC empleando agentes patógenos, químicos, y parasitarios para observar si inducían degranulación o algún cambio en el número de las células; las inyecciones de la toxina de A. salmonicida, compuesto 48/80 (Baccari et al., 2011) (potente agente liberador de histamina) y concanavalina A (Con A), permitieron identificar la degranulación de CGE/MC en trucha arcoíris (Oncorhynchus mykiss), determinando así, que la respuesta ultraestructural era similar a la extrusión anafiláctica de los gránulos en células Mast de mamíferos (Ellis, 1985, Vallejo and Ellis, 1989). La respuesta de las CGE/MC difiere de las células Mast de los mamíferos en dos aspectos: 1) La degranulación involucra la liberación de gránulos electrolucidos intactos y la subsecuente desintegración de la matriz granular (Dezfuli et al., 2008) y 2) La degranulación inducida con el compuesto 48/80 y Con A puede ser inhibida con anti-histaminas prometazina y cimetidina (Baccari et al., 2011). Ultraestructuralmente las CGE/ MC maduras muestran una degranulación crónica no anafiláctica, estos resultados suponen que los precursores residen en el tejido y que las células son capaces de diferenciarse in situ, reforzando la analogía entre este tipo de células y las células mast clásicas de los vertebrados superiores. En cuanto a la asociación con otras células, las CGE/MC y las células rodlet característicamente tienden a rodear un sitio infectado lo que sugiere una integración de la respuesta inflamatoria (Reite, 2005, Mazon et al., 2007, Dezfuli et al., 2008, Dezfuli et al., 2013). Algunas otras correlaciones funcionales de las CGE/MC, incluyen e.g. la calidad del alimento dado a los peces, por ejemplo en salmones alimentados con diferentes calidades de alimento se halló que (con y sin antioxidante etoxiquin) exhibían cambios consistentes en sus características morfológicas y distribución corporal (Jackson et al., 1984). De igual forma, (Sitjà-Bobadilla et al., 2005) Hallaron que al hacer cambios del $100 \%$ en la dieta de Doradas (Sparus aurata) alimentadas con harina de peces, por una fuente proteica vegetal, la ingesta y el crecimiento disminuían dramáticamente, en tanto que a nivel histopatológico se halló aumento de tejido adiposo en el hígado, incremento en el número de vacuolas lipídicas en enterocitos y la submucosa intestinal se hallaba dilatada/hipertrofiada con infiltrados de CGE/MC.

Se ha mostrado que los productos de de granulación de CGE/MC extraídos de la cavidad peritoneal de róbalo (Dicentrarchus labrax) pueden estar involucrados en la respuesta citotóxica contra células tumorales (Cammarata et al., 2000). En tilapia (Oreochromis niloticus) la lisis de las CGE/MC induce una sobrerregulación del $\mathrm{Ca} 2+$ en cultivo de células endoteliales, indicando que los productos de las CGE/MC activan directamente a estas e incrementan la permeabilidad vascular (Matsuyama and lida, 2001). En tilapia (Oreochromis niloticus) además, estas son consideradas reguladoras de la adhesión de neutrófilos a las células endoteliales vasculares en cultivos primarios (Matsuyama and lida, 2002), mientras que en el salmón del atlántico (Salmo salar), representan un componente central del metabolismo del zinc (Paulsen et al., 2001).

\section{Respuestas de las CGE / MC en el Sistema Nervioso de Peces expuestos a tóxicos}

Se ha observado infiltración de CGE/MC de diferentes tamaños y en diferentes estados de degranulación en tejido nervioso, meninges y bulbo olfatorio de peces expuestos a herbicidas, acompañados en muchos casos con un aumento de la tasa de apoptosis de neuronas en el encéfalo (Ramirez-Duarte et al., 2008, Lauriano et al., 2012) esto puede estar relacionado con fenómenos tales como eliminación de células progenitoras con inestabilidad genómica, lo que puede verse reflejado en variaciones cromosomales (Rehen et al., 2001). Lo anterior se vería reforzado por lo descrito por (Marc et al., 2004b) quienes hallaron que productos a base de GP pueden retrasar la progresión del ciclo celular y alterar el proceso de transcripción lo que puede llevar a la génesis de neuronas no aptas. A continuación se describe específicamente lo hallado por (Marc et al., 2004b, Marc et al., 2005). De acuerdo con (Marc et al., 2002, Marc et al., 2003) el GP per se ocasiona un retraso en la transición de la fase G2 a la fase $M$ del ciclo celular por un fallo en la activación del complejo CDK1/ciclina B en trabajos realizados con embriones de erizos de mar en fase temprana de desarrollo. (Marc et al., 2004a) determinaron que el GP (en diferentes productos comerciales conteniendo agentes surfactantes) a una concentración de 0.01 a 0.12 $\mathrm{mM}$ (variable dependiendo del producto comercial y por ende de los compuestos surfactantes presentes en el producto) en una micro-gota asperjada es suficiente para ocasionar una desregulación en la transición del ciclo celular, la cual es inferior a la concentración recomendada por la manufacturera para aspersión de 
40 mM, comparado con la concentración de GP en la aspersión de cultivos de coca y amapola realizada en Colombia que es de $234 \mathrm{mM}$. Adicionalmente, (Marc et al., 2004b) han descrito que los herbicidas a base de GP inhiben la síntesis del ADN durante la fase S. De este modo, el fallo en la progresión de la fase G2 a la fase $\mathrm{M}$ no solo puede ser ocasionada por el fallo en la activación del complejo CDK1/Ciclina B, sino que también puede ser ocasionado por falencias en la replicación del ADN o por ausencia de replicación del ADN, sin descartar alteraciones en otras vías que afecten de forma indirecta la progresión del ciclo celular. De acuerdo a lo anterior, fallas en la progresión del ciclo celular: alteración (reducción o supresión) de la síntesis y/o liberación de factores neurotróficos, lo cual reduce la supervivencia de células progenitoras y de neuronas diferenciadas (Depaepe et al. 2005; Ishamy y Ernfors, 1996; Elshamy et al., 1996; Frade \& Barde, 1999; Lu et al., 2005, Ockel et al., 1996; Putz et al., 2005 citados por (Buss et al., 2006). Otra hipótesis a la tasa alta de apoptosis en el telencéfalo puede recaer en efectos del GP sobre el epitelio olfatorio, dado que en periodos de sinaptogénesis la supervivencia de las neuronas puede depender de factores tróficos liberados por las células inervadas. Está hipótesis se puede ver apoyada en parte por la presencia de centros de proliferación neural en el telencéfalo (Burek y Burke 2004, Chu et al. 2000, Cusato et al. 2001, Lotto et al. 2001, Morcuende et al. 2005, Oliveira et al. 2002, Verney et al. 2000, Vogel et al. 1989, von Bartheld y Johnson 2001 citados por (Buss et al., 2006). El cerebro de los peces a diferencia de los mamíferos se distingue por su habilidad para reemplazar neuronas perdidas (Zupanc, 2006). En los peces es distintivo su enorme potencial para producir continuamente nuevas neuronas en el cerebro adulto, mientras que en los mamíferos la neurogénesis adulta se limita al bulbo olfativo y el hipocampo. En los peces las neuronas no sólo se generan en las estructuras homólogas a esas dos regiones, sino también en docenas de otras áreas del cerebro. En algunas regiones del cerebro de peces, tales como el tectum óptico, las nuevas células se mantienen cerca de zonas de proliferación en el curso de su desarrollo. En otras, como en la mayoría de las subdivisiones del cerebelo, migran, a menudo guiadas por fibras gliales radiales sobre áreas específicas. Aproximadamente el 50\% de las células jóvenes pueden perderse tras someterse a la muerte celular por apoptosis, mientras que las otras sobreviven para el resto de la vida de los peces. Un gran número de células supervivientes se diferencian en neuronas. Según Gheusi et al., 2000; Huang y Bittman, 2002; Lledo y Saghatelyan, 2005; Miwa y Storm, 2005; Petreanu y Alvarez-Buylla, 2002; Rochefort et al., 2002; Zou et al., 2004 citados por (Buss et al., 2006), la privación olfatoria puede inducir una reducción de la supervivencia de neuronas generadas en fase adulta en el bulbo olfatorio. De este modo, es plausible la hipótesis que el aumento de la tasa de apoptosis hallada en peces expuestos a GP sea ocasionada por una menor capacidad de percepción de olores, como fue determinado por (Tierney et al., 2007) quienes hallaron que truchas arcoíris expuestas durante $30 \mathrm{~min}$ a concentraciones de $0.1 \mathrm{mg} / \mathrm{l}$ de GP en la presentación Roundup ${ }^{\circledR}$ reducen la respuesta odorante inducida por la histidina determinada por evaluación comportamental y por medio de un olfato-electrograma. A partir de esto se plantea que alteraciones en el tamaño y morfología de las CGE/CM observadas en el encéfalo y la acumulación de gránulos en su citoplasma pueden ser explicadas según las siguientes hipótesis:

1) inhibición de la liberación del contenido granular con síntesis continua de los componentes granulares, tal vez inducida por algún componente del Roundup, o debido a que las CGE/CM presentes en el encéfalo se encuentran inmaduras y no son capaces de liberar su contenido de acuerdo con lo reportado por (Vallejo and Ellis, 1989)

2) síntesis incrementada de componentes granulares, sin degranulación completa de las mismas, acorde con la actividad de degranulación no citotóxica de las CGE/CM (Vallejo and Ellis, 1989). Probablemente las CGE/CM estén induciendo o acelerando procesos de muerte celular de forma específica e individual para una neurona para lo cual no necesiten llevar a cabo una degranulación completa.

3) el número aumentado de CGE/CM en el bulbo olfatorio hace parte de un mecanismo de remodelación neural seguido al daño neuronal agudo, basado en la evidencia de síntesis y liberación de NGF por mastocitos (Williams et al., 1995) y en la capacidad de neurogeneración y regeneración neuronal en el cerebro de los peces (Zupanc, 2006, Lema et al., 2005).

Los estudios en cachama blanca realizados en la Universidad de los Llanos sobre efectos histopatológicos de la toxicidad aguda por exposición al herbicida GP en Piaractus brachypomus encontraron que las CGE/ MC estaban presentes en meninges y en la corteza del telencéfalo, acompañadas de un patrón de satelitosis alrededor de las neuronas con focos degenerativos, relacionados con la activación o la aceleración de la apoptosis, que sugiere un proceso específico y local (Ramirez-Duarte et al., 2008). Así mismo, al estudiar los efectos combinados del Roundup ${ }^{\circledR}$ y surfactante Cosmoflux ${ }^{\circledR} 411 \mathrm{~F}$ (Ramírez D et al., 2009), se en- 
contraron cambios histopatológicos en las branquias, consistentes en hiperplasia interfilamentar proximal e interlamelar, más severos de acuerdo a la concentración de las sustancias experimentales. Además, se haIló, que en las lesiones del SNC se involucraban células granulares EGC/CM y células gliales asociadas a somas neuronales, los cuales presentan cambios degenerativos y muerte celular, posiblemente relacionados con fenómenos de apoptosis. Las EGC/CM así como células gliales corresponden a líneas celulares pertenecientes al sistema inmune y que regulan la dinámica de reparación: remoción a nivel cerebral así como median algunos procesos vasculares importantes, generándose interrogantes sobre el efecto de dicho xenobióticos en el sistema inmune y su interacción con el tejido nervioso, lo cual permitirá la comprensión más amplia de los fenómenos de respuesta subyacentes ante exposiciones subletales.

Otro trabajo realizado en Colombia (Castañeda, 2012) reafirma la vía olfativa en $P$. brachypomus como posible puerta de entrada al sistema nervioso, se demostró que concentraciones subletales Roundup ${ }^{\circledR}$ Activo $(0.1$ y $1 \mathrm{mg} / \mathrm{l})$ causan alteraciones a nivel tisular en la roseta y bulbo olfativo, con infiltración de CGE/ MC. Este hallazgo apoyaría la idea de que el sistema olfativo es una de las posibles vías de entrada del Roundup ${ }^{\circledR}$ Activo al sistema nervioso central, por lo tanto y teniendo en cuenta que el sistema olfativo está implicado en aspectos fisiológicos importantes para los peces como la alimentación, la reproducción y el reconocimiento intra e inter específico; exposiciones prolongadas a este herbicida podrían afectar estos procesos vitales para el desarrollo y su interacción con el ambiente. Se ha considerado que las CGE/ MC podrían usarse como biomarcador, toda vez que el término hace referencia a los cambios celulares, bioquímicos, moleculares, o fisiológicos que son medidos en células, fluidos, tejidos u órganos dentro de un organismo y que indican la exposición o efecto de un xenobiótico (Lourenço et al., 2011, Pacheco and Santos, 2002). Se ha demostrado, que la exposición a herbicidas aumenta la expresión de CGE/MC en el cerebro, las cuales generan aminas vasoactivas, e. $g$ de serotonina -5-HT- que actúa en el eje hipotalámico pituitario interrenal (EHPI), ocasionando la liberación de cortisol, el cual se une a nivel intracelular al receptor de glucocorticoide (GR), inhibiendo el factor NF-kB y por consiguiente la síntesis de citoquinas (Rondón Barragán et al., 2010). Así mismo, en tilapia (Oreochromis niloticus), se observaron cambios histopatológicos en hígado y cerebro expuestos a insecticida endosulfano -reconocidos por ser altamente tóxicos en peces -. En el cerebro se observó meningitis, en- cefalitis y edema, con un infiltrado inflamatorio asociado de CGE/ MC (Matthiessen and Roberts, 1982). (Figueiredo-Fernandes et al., 2007), visualizaron CGE/ MC a nivel del complejo venoso pancreático mayor de tilapia (Oreochromis niloticus) luego de la exposición a cobre; así mismo, (Coimbra et al., 2007) Observaron la presencia de CGE/MC y macrófagos en esta área, luego de una exposición dietaria a diferentes niveles de endosulfano -durante 21 y 35 días-, un insecticida ampliamente distribuido en el mundo, y cuyo agravante es su capacidad de transferirse a través de la cadena trófica; el análisis cualitativo mostró un incremento en el número de CGE/MC así como la migración de las mismas desde áreas cercanas a los vasos sanguíneos hasta el parénquima hepático. Las alteraciones a nivel branquial, así como la infiltración de CGE/MC fue registrada por (Teh et al., 1997), donde las halló asociadas a linfocitos, células plasmáticas y macrófagos; tales cambios fueron atribuidos a contaminantes en el medio acuático. Recientemente (Lauriano et al., 2012) estudiaron el papel de las CGE/MC en intestino y branquias de Dorada (Sparus aurata) expuesto a bifenilos policlorados (РCB 126); este estudio analizó la localización morfológica y la proliferación de los CGE/MC en el intestino y branquias después de una exposición de 12 h, 24 o 72 a PCB 126, un bifenilo policlorado, que es un agente inmunotóxico potente. En los órganos de los peces expuestos a PCB 126, se observó que, además de la congestión de los vasos sanguíneos, no había extravasación de las células rojas de la sangre, la infiltración de linfocitos, y un aumento progresivo en el número de CGE/MC. Estos datos confirman la acción inmunotóxica de PCB y la participación de las CGE/MC en la respuesta inflamatoria.

De otra parte, (Figueiredo-Fernandes et al., 2006) haIlaron que la exposición de tilapia (Oreochromis niloticus) a paraquat, ocasionó alteraciones del parénquima hepático, como vacuolización, necrosis, incremento de la agregación de macrófagos y CGE/MC, asociados a una reducción de la capacidad de biotransformación hepática. En relación con los ecosistemas acuáticos, los peces han sido uno de los primeros en ser utilizados en los protocolos de evaluación y como especies centinelas, ya que la característica más importante, es que están en la cumbre de la cadena trófica pudiendo afectar la salud humana, lo cual aumenta su importancia en los estudios ambientales (Zhou et al., 2008). El uso combinado de biomarcadores bioquímicos, genéticos e histológicos es una herramienta útil para la investigación de los efectos inducidos por contaminantes ambientales, que permite establecer la relación entre la exposición al contaminante y las diversas respuestas biológicas (Pacheco and Santos, 2002, Teh et 
al., 1997), así como su grado de afectación a distintos niveles -molecular, celular, tisular- (Valdez Domingos et al., 2007, Viarengo et al., 2007, Ben Ameur et al., 2012, Vieira et al., 2014). Particularmente, las alteraciones histopatológicas pueden modificar significativamente la función de tejidos y células señalando así los efectos de exposición a agentes tóxicos (Pacheco and Santos, 2002, Lourenço et al., 2011). Dichos cambios dependerán de la capacidad del organismo para reparar la injuria, la naturaleza y la severidad de la contaminación y el tiempo de exposición (Lourenço et al., 2011). Los productos basados en GP son generalmente más tóxicos para los peces (Lushchak et al., 2009, Moreno et al., 2014) que para animales terrestres, se ha observado que la exposición a herbicidas aumenta la expresión de $\mathrm{MC}$ en diversos tejidos -e.g. cerebro, branquias, intestino- (Matthiessen and Roberts, 1982, Teh et al., 1997, Ramirez-Duarte et al., 2008, Ramírez D et al., 2009, Rondón Barragán et al., 2010, Lauriano et al., 2012), lo cual resalta la importancia de realizar un cuidadoso monitoreo del impacto potencial del GP sobre la biota acuática tropical (Alvarez-Moya et al., 2014, Moreno et al., 2014).

Como se ha descrito a través de esta revisión, las CGE/ MC están involucradas en la respuesta inmune ante agentes nocivos -e.g. bacterias y sus productos, parásitos, tóxicos-, integrar a esta población celular como bioindicador de respuesta de teleósteos ante productos tóxicos, puede ser una opción para futuras investigaciones, dado que entre más se combinen factores biológicos, se podrá dilucidar mejor la relación entre la respuesta y el contaminante. Finalmente, las CGE/ MC son una población celular de la cual no se ha determinado completamente la función en el sistema inmune de peces neotropicales, por dicha razón incluirla como un biomarcador en estudios de toxicología con pesticidas usados frecuentemente en nuestro medio proporcionará más elementos para entender sus mecanismos y la relevancia de las mismas en lo que respecta a respuestas complejas de tipo neuro-endocrino e inmune, como en los procesos de alarma y reparación ante agentes xenobióticos presentes en el medio acuático.

\section{Referencias}

Acosta J, Montero V, Carpio Y, Velázquez J, Garay HE, Reyes O, Cabrales A, Masforrol Y, Morales A, Estrada MP. Cloning and functional characterization of three novel antimicrobial peptides from tilapia (Oreochromis niloticus). Aquaculture. 2013;(372-375): 9-18.

Ahmad I, Hamid T, Fatima M, Chand HS, Jain SK, Athar M, Raisuddin S. Induction of hepatic antioxidants in freshwater catfish (Chan- na punctatus Bloch) is a biomarker of paper mill effluent exposure. Biochim Biophys Acta. 2000;1523:37-48.

Albinati ACL, Moreira ELT, Albinati RCB, Carvalho JV, Santos GB, Lira AD. 2007. Toxicidade aguda do herbicida roundup ${ }^{\circledR}$ para piauçu ("Leporinus macrocephalus"). Rev Bras Saúde Prod An. 2007;8(3):184-192.

Alejo A, Tafalla C. Chemokines in teleost fish species. Dev Comp Immunol 2011;35:1215-1222.

Alvarez-Moya C, Silva MR, Arambula AR, Sandoval AI, Vasquez $\mathrm{HC}$, Gonzalez- Montes RM. Evaluation of genetic damage induced by glyphosate isopropylamine salt using Tradescantia bioassays. Genet Mol Biol. 2011;34:127-130.

Alvarez-Moya C, Silva MR, Ramírez CV, Gallardo DG, Sánchez RL, Aguirre AC, Velasco AF. Comparison of the in vivo and in vitro genotoxicity of glyphosate isopropylamine salt in three different organisms. Genet Mol Biol. 2014;37:105-110.

Alvarez-Pellitero P. Fish immunity and parasite infections: from innate immunity to immunoprophylactic prospects. Vet Immunol Immunopathol. 2008;126:171-198.

Allen SL. Regulatory aspects of neurotoxicity assessment. In: Krieger RI, editor. Hayes' Handbook of Pesticide Toxicology. Elsevier; New York: 2010;3(1):587-602.

Amarante Junior OPD, Santos TCRD, Brito NM, Ribeiro ML. Glifosato: propriedades, toxicidade, usos e legislação. Química Nova. 2002;25:589-593.

Antón FA, Laborda E, De Ariz M. Acute toxicity of the herbicide glyphosate to fish. Chemosphere. 1994;28:745-753.

Baccari GC, Pinelli C, Santillo A, Minucci S, Rastogi RK. Mast cells in nonmammalian vertebrates: an overview. Int Rev Cell Mol Biol. 2011;290:1-53.

Bao B, Peatman E, Xu P, Li P, Zeng H, He C, Liu Z. The catfish liverexpressed antimicrobial peptide 2 (LEAP-2) gene is expressed in a wide range of tissues and developmentally regulated. Mol Immunol. 2006;43:367-77.

Ben Ameur W, De Lapuente J, El Megdiche Y, Barhoumi B, Trabelsi S, Camps L, Serret J, Ramos-Lopez D, Gonzalez-Linares J, Driss MR, Borras M. Oxidative stress, genotoxicity and histopathology biomarker responses in mullet (Mugil cephalus) and sea bass (Dicentrarchus labrax) liver from Bizerte Lagoon (Tunisia). Mar Pollut Bull. 2012;64:241-51.

Blackstock N, Pickering AD. Acidophilic granular cells in the epidermis of the brown trout, Salmo trutta L. Cell Tissue Res. 1980;210:359-69.

Bolognesi C, Carrasquilla G, Volpi S, Solomon KR, Marshall EJ. Biomonitoring of genotoxic risk in agricultural workers from five colombian regions: association to occupational exposure to glyphosate. J Toxicol Environ Health A. 2009;72:986-997.

Borggaard OK, Gimsing AL. Fate of glyphosate in soil and the possibility of leaching to ground and surface waters: a review. Pest Manag Sci. 2008;64:441-56.

Buonocore F, Randelli E, Casani D, Picchietti S, Belardinelli MC, De Pascale D, De Santi C, Scapigliati G. A piscidin-like anti- 
microbial peptide from the icefish Chionodraco hamatus (Perciformes: Channichthyidae): molecular characterization, localization and bactericidal activity. Fish Shellfish Immunol 2012;33:1183-1191.

Buss RR, Sun W, Oppenheim RW. Adaptive roles of programmed cell death during nervous system development. Annu Rev Neurosci. 2006;29:1-35.

Cammarata M, Vazzana M, Cervello $M$, Arizza V, Parrinello N. Spontaneous cytotoxic activity of eosinophilic granule cells separated from the normal peritoneal cavity ofDicentrarchus labrax. Fish Shellfish Immunol. 2000;10:143-154.

Castañeda CD. 2012. Descripción de las vías olfativas (roseta - bulbo olfativo) y evaluación de los efectos histopatológicos causados por el Roundup ${ }^{\circledR}$ activo sobre el sistema olfativo de alevinos de cachama blanca (Piaractus brachypomus). Biologo, Universidad Militar Nueva Granada.

Cavalcante DG, Martinez CB, Sofia SH. Genotoxic effects of Roundup on the fish Prochilodus lineatus. Mutat Res. 2008;655:41-46.

Cavas T, Konen S. Detection of cytogenetic and DNA damage in peripheral erythrocytes of goldfish (Carassius auratus) exposed to a glyphosate formulation using the micronucleus test and the comet assay. Mutagenesis. 2007;22:263-268.

Cazenave J, Bacchetta C, Parma MJ, Scarabotti PA, Wunderlin DA. Multiple biomarkers responses in Prochilodus lineatus allowed assessing changes in the water quality of Salado River basin (Santa Fe, Argentina). Environ Pollut. 2009;157:3025-3033.

Coimbra AM, Figueiredo-Fernandes A, Reis-Henriques MA. Nile tilapia (Oreochromis niloticus), liver morphology, CYP1A activity and thyroid hormones after Endosulfan dietary exposure. Pestic Biochem Physiol. 2007;89:230-236.

Corrales J, Mulero I, Mulero V, Noga EJ. Detection of antimicrobial peptides related to piscidin 4 in important aquacultured fish. Dev Comp Immunol. 2010;34: 331-43.

Cuesta A, Meseguer J, Esteban MA. Molecular and functional characterization of the gilthead seabream beta-defensin demonstrate its chemotactic and antimicrobial activity. Mol Immunol. 2011;48:1432-1438.

Chang $\mathrm{Cl}$, Zhang YA, Zou J, Nie P, Secombes CJ. Two cathelicidin genes are present in both rainbow trout (Oncorhynchus mykiss) and atlantic salmon (Salmo salar). Antimicrob Agents Chemother. 2006;50:185-195.

Chekmenev EY, Vollmar BS, Forseth KT, Manion MN, Jones SM, Wagner TJ, Endicott RM, Kyriss BP, Homem LM, Pate M, He J, Raines J, Gor'kov PL, Brey WW, Mitchell DJ, Auman AJ, Ellard-Ivey MJ, Blazyk J, Cotten M. Investigating molecular recognition and biological function at interfaces using piscidins, antimicrobial peptides from fish. Biochim Biophys Acta. 2006;1758:1359-1372.

Da'as S, Teh EM, Dobson JT, Nasrallah GK, Mcbride ER, Wang H, Neuberg DS, Marshall JS, Lin TJ, Berman JN. Zebrafish mast cells possess an FcvarepsilonRI-like receptor and participate in innate and adaptive immune responses. Dev Comp Immunol. 2011:35:125-134.
Da'as SI, Coombs AJ, Balci TB, Grondin CA, Ferrando A A, Berman $J N$. The zebrafish reveals dependence of the mast cell lineage on Notch signaling in vivo. Blood. 2012;119:3585-94.

De Roos AJ, Blair A, Rusiecki JA, Hoppin JA, Svec M, Dosemeci M, Sandler DP, Alavanja MC. Cancer incidence among glyphosateexposed pesticide applicators in the Agricultural Health Study. Environ Health Perspect. 2005;113:49-54.

Dezfuli BS, Giari L, Lui A, Lorenzoni M, Noga EJ. Mast cell responses to Ergasilus (Copepoda), a gill ectoparasite of sea bream. Fish Shellfish Immunol. 2011;30: 1087-94.

Dezfuli BS, Giovinazzo G, Lui A, Giari L. Inflammatory response to Dentitruncus truttae (Acanthocephala) in the intestine of brown trout. Fish Shellfish Immun. 2013;36:577-585.

Dezfuli BS, Lui A, Pironi F, Manera M, Shinn AP, Lorenzoni M. Cell types and structures involved in tench, Tinca tinca (L.), defence mechanisms against a systemic digenean infection. J Fish Dis. 2013; 36: 577-85

Dimitrov BD, Gadeva PG, Benova DK, Bineva MV. Comparative genotoxicity of the herbicides Roundup, Stomp and Reglone in plant and mammalian test systems. Mutagenesis. 2006;21: 375-382.

Dobson JT, Seibert J, Teh EM, Da'as S, Fraser RB, Paw BH, Lin TJ, Berman JN. Carboxypeptidase A5 identifies a novel mast cell lineage in the zebrafish providing new insight into mast cell fate determination. Blood. 2008;112: 2969-72.

Douglas SE, Gallant JW, Gong Z, Hew C. Cloning and developmental expression of a family of pleurocidin-like antimicrobial peptides from winter flounder, Pleuronectes americanus (Walbaum). Dev Comp Immunol. 2001;25:137-47.

Douglas SE, Gallant JW, Liebscher RS, Dacanay A, Tsoi SCM. Identification and expression analysis of hepcidin-like antimicrobial peptides in bony fish. Dev Comp Immunol. 2003;27:589-601.

Duke SO, Powles SB. Glyphosate: a once-in-a-century herbicide. Pest Manag Sci 2008;64:319-325.

Elie-Caille C, Heu C, Guyon C, Nicod L. Morphological damages of a glyphosate-treated human keratinocyte cell line revealed by a micro- to nanoscale microscopic investigation. Cell Biology and Toxicology. 2010;26:331-339.

Ellis AE. Eosinophilic granular cells (EGC) and histamine responses to Aeromonas salmonicida toxins in rainbow trout. Dev Comp Immunol. 1985;9:251-260.

EPA. 2012. Herbicides [Online]. US. Available: http://www.epa.gov/ caddis/ssr_herb_int.html [Accessed 09/02/ 2015].

Evrard E, Marchand J, Theron M, Pichavant-Rafini K, Durand G, Quiniou $\mathrm{L}$, Laroche J. Impacts of mixtures of herbicides on molecular and physiological responses of the European flounder Platichthys flesus. Comp Biochem Physiol C Toxicol Pharmacol. 2010;152:321-331.

Ferreira D, Da Motta AC, Kreutz LC, Toni C, Loro VL, Barcellos LJ. Assessment of oxidative stress in Rhamdia quelen exposed to agrichemicals. Chemosphere. 2010;79:914-921. 
Figueiredo-Fernandes A, Fontaínhas-Fernandes A, Rocha E, ReisHenriques MA. The Effect of Paraquat on Hepatic EROD Activity, Liver, and Gonadal Histology in Males and Females of Nile Tilapia, Oreochromis niloticus, Exposed at Different Temperatures. Arch Environ Contam Toxicol. 2006;51:626-632.

Figueiredo-Fernandes AM, Fontainhas-Fernandes AA, Monteiro RA, Reis-Henriques MA, Rocha E. Spatial relationships of the intrahepatic vascular-biliary tracts and associated pancreatic acini of Nile tilapia, Oreochromis niloticus (Teleostei, Cichlidae): a serial section study by light microscopy. Ann Anat. 2007; 189:17-30.

Folmar LC, Sanders HO, Julin AM. Toxicity of the herbicide glyphosate and several of its formulations to fish and aquatic invertebrates. Arch Environ Contam Toxicol. 1979;8:269-278.

Galli SJ, Kalesnikoff J, Grimbaldeston MA, Piliponsky AM, Williams CM, Tsai M. Mast cells as "tunable" effector and immunoregulatory cells: recent advances. Annu Rev Immunol. 2005;23:749-786.

Garg TK, Domingos FXV, Almeida-Val VMF, Val AL. Histochemistry and functional organization of the dorsal skin of Ancistrus dolichopterus (Siluriformes: Loricariidae). Neotrop Ichthyol. 2010;8:877-884

Giesy JP, Dobson S, Solomon KR. Ecotoxicological Risk Assessment for Roundup Herbicide. Rev Environ Contam Toxicol. 2000; 167:35-120.

Glusczak L, Miron Ddos S, Moraes BS, Simoes RR, Schetinger MR, Morsch VM, Loro VL. Acute effects of glyphosate herbicide on metabolic and enzymatic parameters of silver catfish (Rhamdia quelen). Comp Biochem Physiol C Toxicol Pharmacol. 2007;146:519-524.

Gomez D, Sunyer JO, Salinas I. The mucosal immune system of fish: The evolution of tolerating commensals while fighting pathogens. Fish Shellfish Immunol. 2013;35:1729-1739.

Guilherme S, Gaivao I, Santos MA, Pacheco M. DNA damage in fish (Anguilla anguilla) exposed to a glyphosate-based herbicide -elucidation of organ-specificity and the role of oxidative stress. Mutat Res. 2012;743:1-9.

Hellberg H, Bjerkas I, Vagnes OB, Noga EJ. Mast cells in common wolffish Anarhichas lupus L.: ontogeny, distribution and association with lymphatic vessels. Fish Shellfish Immunol. 2013;35:1769-1778.

Hildebrand LD, Sullivan DS, Sullivan TP. Experimental studies of rainbow trout populations exposed to field applications of Roundup herbicide. Arch Environ Contam Toxicol. 1982;11:93-98.

Holland JW, Rowley AF. Studies on the eosinophilic granule cells in the gills of the rainbow trout, Oncorhynchus mykiss. Comp Biochem Physiol C Pharmacol Toxicol Endocrinol. 1998;120:321-328.

Howe CM, Berrill M, Pauli BD, Helbing CC, Werry K, Veldhoen N. Toxicity of glyphosate-based pesticides to four North American frog species. Environ Toxicol Chem. 2004;23:1928-1938.

Jackson AJ, Kerr AK, Cowey CB. Fish silage as a dietary ingredient for salmon. I. Nutritional and storage characteristics. Aquaculture. 1984;38:211-220.

Jarrard HE, Delaney KR, Kennedy CJ. Impacts of carbamate pesticides on olfactory neurophysiology and cholinesterase acti- vity in coho salmon (Oncorhynchus kisutch). Aquat Toxicol. 2004;69:133-148.

Jiraungkoorskul W, Upatham ES, Kruatrachue M, Sahaphong S, Vichasri-Grams S, Pokethitiyook P.Biochemical and histopathological effects of glyphosate herbicide on Nile tilapia (Oreochromis niloticus). Environ Toxicol. 2003;18:260-267.

Jiraungkoorskula W, Upathama ES, Kruatrachuea M, Sahaphongc S, Vichasri-Gramsa S, Pokethitiyooka P. Histophatological effects of Roundup, a glyphosate herbicide, on Nile tilapia (Oreochromis niloticus). Sci Asia. 2002;28:121-127.

Jordanova M, Miteva N, Rocha E. A quantitative study of the hepatic eosinophilic granule cells and rodlet cells during the breeding cycle of Ohrid trout, Salmo letnica Kar. (Teloestei, Salmonidae). Fish Shellfish Immunol. 2007;23:473-478.

Kelly DW, Poulin R, Tompkins DM, Townsend CR. Synergistic effects of glyphosate formulation and parasite infection on fish malformations and survival. J Appl Ecol. 2010;47:498-504.

Kolpin DW, Thurman EM, Lee EA, Meyer MT, Furlong ET, Glassmeyer ST. Urban contributions of glyphosate and its degradate AMPA to streams in the United States. Sci Total Environ. 2006;354:191-197.

Kunder CA, St John AL, Abraham SN. Mast cell modulation of the vascular and lymphatic endothelium. Blood. 2011;118: 5383-5393.

Langiano C, Martinez CB. Toxicity and effects of a glyphosate-based herbicide on the Neotropical fish Prochilodus lineatus. Comp Biochem Physiol C Toxicol Pharmacol. 2008;147:222-231.

Lauriano ER, Calo M, Silvestri G, Zaccone D, Pergolizzi S, Lo Cascio P. Mast cells in the intestine and gills of the sea bream, Sparus aurata, exposed to a polychlorinated biphenyl, PCB 126. Acta Histochem. 2012;114:166-171.

Lauth X, Shike H, Burns JC, Westerman ME, Ostland VE, Carlberg JM, Van Olst JC, Nizet V, Taylor SW, Shimizu C, Bulet P. Discovery and characterization of two isoforms of moronecidin, a novel antimicrobial peptide from hybrid striped bass. J Biol Chem. 2002;277:5030-5039.

Leknes IL. Eosinophilic granule cells and endocytic cells in intestinal wall of pearl gouramy (Anabantidae: Teleostei). Fish Shellfish Immunol. 2007;23:897-900.

Lema SC, Hodges MJ, Marchetti MP, Nevitt GA. Proliferation zones in the salmon telencephalon and evidence for environmental influence on proliferation rate. Comp Biochem Physiol A Mol Integr Physiol. 2005;141:327-335.

Lourenço J, Silva A, Carvalho F, Oliveira J, Malta M, Mendo S, Gonçalves F, Pereira R. Histopathological changes in the earthworm Eisenia andrei associated with the exposure to metals and radionuclides. Chemosphere. 2011;85:1630-1634.

Lushchak OV, Kubrak OI, Storey JM, Storey KB, Lushchak VI. Low toxic herbicide Roundup induces mild oxidative stress in goldfish tissues. Chemosphere, 2009;76:932-937.

Marc J, Bellé R, Morales J, Cormier P, Mulner-Lorillon O. Formulated Glyphosate Activates the DNA-Response Checkpoint of the Cell Cycle Leading to the Prevention of G2/M Transition. Toxicol Sci. 2004a;82:436-442. 
Marc J, Le Breton M, Cormier P, Morales J, Belle R, Mulner-Lorillon O. A glyphosate-based pesticide impinges on transcription. Toxicol Appl Pharmacol. 2005;203:1-8.

Marc J, Mulner-Lorillon O, Belle R. Glyphosate-based pesticides affect cell cycle regulation. Biol Cell. 2004b;96: 245-249.

Marc J, Mulner-Lorillon O, Boulben S, Hureau D, Durand G, BeIle R. Pesticide Roundup provokes cell division dysfunction at the level of CDK1/cyclin B activation. Chem Res Toxicol. 2002;15:326-331.

Marc J, Mulner-Lorillon O, Durand G, Belle R. Embryonic cell cycle for risk assessment of pesticides at the molecular level. Environ Chem Lett. 2003;1:8-12.

Marchand J, Tanguy A, Charrier G, Quiniou L, Plee-Gauthier E, Laroche J. Molecular identification and expression of differentially regulated genes of the European flounder, Platichthys flesus, submitted to pesticide exposure. Mar Biotechnol (NY). 2006;8:275-294.

Matsuyama T, lida T. Degranulation of eosinophilic granular cells with possible involvement in neutrophil migration to site of inflammation in tilapia. Dev Comp Immunol. 1999;23:451-457.

Matsuyama T, lida T. Influence of tilapia mast cell lysate on vascular permeability. Fish Shellfish Immunol. 2001;11:549-556.

Matsuyama T, lida T. Tilapia mast cell lysates enhance neutrophil adhesion to cultured vascular endothelial cells. Fish Shellfish Immunol. 2002;13:243-250.

Matthiessen P, Roberts RJ. Histopathological changes in the liver and brain of fish exposed to endosulfan insecticide during tsetse fly control operations in Botswana. J Fish Dis. 1982;5:153-159.

Mazon AF, Huising MO, Taverne-Thiele AJ, Bastiaans J, Verburg-Van Kemenade BM. The first appearance of Rodlet cells in carp (Cyprinus carpio L.) ontogeny and their possible roles during stress and parasite infection. Fish Shellfish Immunol. 2007;22:27-37.

Mitchell DG, Chapman PM, Long TJ. Acute toxicity of Roundup and Rodeo herbicides to rainbow trout, chinook, and coho salmon. Bull Environ Contam Toxicol. 1987;39:1028-1035.

Modesto KA, Martinez CB. Effects of Roundup Transorb on fish: hematology, antioxidant defenses and acetylcholinesterase activity. Chemosphere. 2010a;81: 781-787.

Modesto KA, Martinez CB. Roundup causes oxidative stress in liver and inhibits acetylcholinesterase in muscle and brain of the fish Prochilodus lineatus. Chemosphere. 2010b;78:294-299.

Monheit S. 2003. Glyphosate - based aquatic herbicides an overview of risk [Online]. Available: https://scholar.google.com.co/scholar?q=Glyphosate+-+based+aquatic + h erbicides+an+overview+of+risk.\&hl=es\&as_sdt $=0 \&$ as vis=1\&oi=scholart\&sa=X\&ei=-g_ZVKWdI8OVNrKUgZAL\&ved $=0 C B o Q g Q M w A A$ [Accessed 09/02 2015].

Monsanto. 2010. Roundup Transorb [Online]. Available: http://monsanto.com.br/produtos/herbicidas/fichas-deemergencia-e-bulas/ pdf/roundup-transorb-bula.pdf [Accessed 02/20/2015 2015].

Moreno NC, Sofia SH, Martinez CB. Genotoxic effects of the herbicide Roundup Transorb and its active ingredient glyphosate on the fish Prochilodus lineatus. Environ Toxicol Pharmacol. 2014;37:448-454.

Mortensen DA, Franklin Egan J, Maxwell BD, Ryan MR, Smith RG. Navigating a Critical Juncture for Sustainable Weed Management. Bio Science. 2012; 62: 9.

Mulero I, Noga EJ, Meseguer J, Garcia-Ayala A, Mulero V. The antimicrobial peptides piscidins are stored in the granules of professional phagocytic granulocytes of fish and are delivered to the bacteria-containing phagosome upon phagocytosis. Dev Comp Immunol. 2008;32:1531-1538.

Mulero I, Sepulcre MP, Meseguer J, Garcia-Ayala A, Mulero V. Histamine is stored in mast cells of most evolutionarily advanced fish and regulates the fish inflammatory response. Proc Natl Acad Sci USA. 2007;104:19434-19439.

Mutoloki S, Reite OB, Brudeseth B, Tverdal A, Evensen O. A comparative immunopathological study of injection site reactions in salmonids following intraperitoneal injection with oil-adjuvanted vaccines. Vaccine. 2006;24:578-588.

Neskovic NK, Poleksic V, Elezovic I, Karan V, Budimir M. Biochemical and histopathological effects of glyphosate on carp, Cyprinus carpio L. Bull Environ Contam Toxicol. 1996;56:295-302.

Niu SF, Jin Y, Xu X, Qiao Y, Wu Y, Mao Y, Su YQ, Wang J. Characterization of a novel piscidin-like antimicrobial peptide from Pseudosciaena crocea and its immune response to Cryptocaryon irritans. Fish Shellfish Immunol. 2013;35:513-524.

Nivia E. 2001. Las Guerras en Colombia: Drogas, Armas y Petróleo. Drugs, Guns and Oil [Online]. Davis,CA: Universidad de California. Available: http://www.glifocidio.org/docs/plan\%20colombia\%20doc/pc13.pdf [Accessed 15-02-2015. 2015].

Noga EJ, Ullal AJ, Corrales J, Fernandes JM. Application of antimicrobial polypeptide host defenses to aquaculture: Exploitation of downregulation and upregulation responses. Comp Biochem Physiol Part D Genomics Proteomics. 2011;6:44-54.

Pacheco M, Santos MA. Biotransformation, genotoxic, and histopathological effects of environmental contaminants in European eel (Anguilla anguilla L.). Ecotoxicol Environ Saf. 2002;53:331347.

Patrzykat A, Gallant JW, Seo JK, Pytyck J, Douglas SE. Novel Antimicrobial Peptides Derived from Flatfish Genes. Antimicrobial Agents and Chemotherapy. 2003;47:2464-2470.

Paulsen SM, Sveinbjørnsson B, Robertsen B. Selective staining and disintegration of intestinal eosinophilic granule cells in Atlantic salmon after intraperitoneal injection of the zinc chelator dithizone. J Fish Biol. 2001;58:768-775.

Paz-Y-Mino C, Davalos MV, Sanchez ME, Arevalo M, Leone PE. Should gaps be included in chromosomal aberration analysis? Evidence based on the comet assay. Mutat Res. 2002;516:5761.

Peixoto F. Comparative effects of the Roundup and glyphosate on mitochondrial oxidative phosphorylation. Chemosphere. 2005;61:1115-1122.

Peterson RKD, Hulting AG. A comparative ecological risk assessment for herbicides used on spring wheat: the effect of glyphosate 
when used within a glyphosate-tolerant wheat system. Weed Science. 2004;52:834-844.

Powell MD, Wright GM, Burka JF. Morphological and distributional changes in the eosinophilic granule cell (EGC) population of the rainbow trout (Oncorhynchus mykiss walbaum) intestine following systemic administration of capsaicin and substance P. J Exp Zool. 1993;266:19-30.

Press CM, Evensen $\varnothing$. The morphology of the immune system in teleost fishes. Fish Shellfish Immun. 1999;9:309-318.

Prykhozhij SV, Berman JN. The progress and promise of zebrafish as a model to study mast cells. Dev Comp Immunol. 2014;46:7483.

Ramirez-Duarte WF, Rondon-Barragan IS, Eslava-Mocha PR. Acute toxicity and histopathological alterations of Roundup ${ }^{\circledR}$ herbicide on "cachama blanca" (Piaractus brachypomus). Pesq Vet Bras. 2008;28(11):547-554.

Ramírez DW, Rondón BI, Vidal BH, Eslava MP. TOXICIDAD AGUDA Y LESIONES HISTOPATOLÓGICAS EN CACHAMA BLANCA (Piaractus brachypomus) EXPUESTAS A LA MEZCLA DE HERBICIDA ROUNDUP $®$ MÁS SURFACTANTE COSMOFLUX® 411F. Revista MVZ Córdoba. 2009;14:1563-1575.

Reber LL, Marichal T, Galli SJ. New models for analyzing mast cell functions in vivo. Trends Immuno. 2012;33:613-625.

Rehen SK, Mcconnell MJ, Kaushal D, Kingsbury MA, Yang AH, Chun J. Chromosomal variation in neurons of the developing and adult mammalian nervous system. Proceedings of the National Academy of Sciences. 2001;98:13361-13366.

Reite OB. The mast cell nature of granule cells in the digestive tract of the pike,Esox lucius: similarity to mammalian mucosal mast cells and globule leucocytes. Fish Shellfish Immun. 1996;6:363-369.

Reite OB. Mast cells/eosinophilic granule cells of salmonids: staining properties and responses to noxious agents. Fish Shellfish Immun. 1997;7:567-584.

Reite OB. Mast cells/eosinophilic granule cells of teleostean fish: a review focusing on staining properties and functional responses. Fish Shellfish Immun. 1998;8:489-513.

Reite OB. The rodlet cells of teleostean fish: their potential role in host defence in relation to the role of mast cells/eosinophilic granule cells. Fish Shellfish Immun. 2005;19:253-267.

Reite OB, Evensen $\varnothing$. Inflammatory cells of teleostean fish: A review focusing on mast cells/eosinophilic granule cells and rodlet cells. Fish Shellfish Immun. 2006;20:192-208.

Relyea RA. THE IMPACT OF INSECTICIDES AND HERBICIDES ON THE BIODIVERSITY AND PRODUCTIVITY OF AQUATIC COMMUNITIES. Ecol Appl. 2005;15: 618-627.

Roberts RJ, Young H, Milne JA. Studies on the skin of plaice (Pleuronectes platessa L.). J Fish Biol. 1972;4:87-98.

Rodriguez B, Almeida F. 2005. Guia De Herbicidas, Londrina, Uel Editora.

Rombout JHWM, Abelli L, Picchietti S, Scapigliati G, Kiron V. Teleost intestinal immunology. Fish Shellfish Immun. 2011;31(5):616-626.
Rondón Barragán I, Pardo Hernández D, Eslava Mocha P. Efecto de los herbicidas sobre el sistema inmune: una aproximación en peces. RCCV. 2010;4(1):1-22.

Salbego J, Pretto A, Gioda CR, De Menezes CC, Lazzari R, Radunz Neto J, Baldisserotto B, Loro VL. Herbicide formulation with glyphosate affects growth, acetylcholinesterase activity, and metabolic and hematological parameters in piava (Leporinus obtusidens). Arch Environ Contam Toxicol. 2010;58:740-745.

Salerno G, Parrinello N, Roch P, Cammarata M. cDNA sequence and tissue expression of an antimicrobial peptide, dicentracin; a new component of the moronecidin family isolated from head kidney leukocytes of sea bass, Dicentrarchus labrax. Comp Biochem Physiol B Biochem Mol Biol. 2007;146:521-529.

Secombes C, Cunningham C. Cytokines: an evolutionary perspective: Forward. Dev Comp Immunol. 2004;28:373-374.

Secombes CJ, Wang T, Hong S, Peddie S, Crampe M, Laing KJ, Cunningham C, Zou J. Cytokines and innate immunity of fish. Dev Comp Immunol. 2001;25:713-723.

Sfacteria A, Brines $M$, Blank $U$. The mast cell plays a central role in the immune system of teleost fish. Mol Immunol. 2015;63: 3-8.

Shiogiri NS, Paulino MG, Carraschi SP, Baraldi FG, Da Cruz C, Fernandes MN. Acute exposure of a glyphosate-based herbicide affects the gills and liver of the Neotropical fish, Piaractus mesopotamicus. Environ Toxicol Pharmacol. 2012;34: 388-396.

Silphaduang U, Noga EJ. Antimicrobials: Peptide antibiotics in mast cells of fish. Nature. 2001;414:268-269.

Silver R, Curley JP. Mast cells on the mind: new insights and opportunities. Trends Neurosci. 2013;36:513-521.

Sitjà-Bobadilla A, Peña-Llopis S, Gómez-Requeni P, Médale F, Kaushik S, Pérez-Sánchez J. Effect of fish meal replacement by plant protein sources on non-specific defence mechanisms and oxidative stress in gilthead sea bream (Sparus aurata). Aquaculture. $2005 ; 249: 387-400$.

Sivikova K, Dianovsky J. Cytogenetic effect of technical glyphosate on cultivated bovine peripheral lymphocytes. Int J Hyg Environ Health. 2006;209:15-20.

Solomon KR, Dalhoff K, Volz D, Van Der Kraak G. 2013. 7 - Effects Of Herbicides On Fish. In: Keith B. Tierney, A. P. F. \& Colin, J. B. (eds.) Fish Physiology. Academic Press.

Sparling DW, Matson C, Bickham J, Doelling-Brown P. Toxicity of glyphosate as Glypro and LI700 to red-eared slider (trachemys scripta elegans) embryos and early hatchlings. Environ Toxicol Chem. 2006;25:2768-2774.

Sperstad SV, Haug T, Blencke HM, Styrvold OB, Li C, Stensvag K. Antimicrobial peptides from marine invertebrates: challenges and perspectives in marine antimicrobial peptide discovery. Biotechnol Adv. 2011;29:519-530.

Sutterlin A, Sutterlin N, Rand S. 1971. The Influence of Synthetic Surfactants on the Functional Properties of the Olfactory Epithelium of Atlantic Salmon. In: CANADA, F. R. B. O. (ed.). Thechnical Report No. 287. p.p. 2-8 
Szarek J, Siwicki A, Andrzejewska A, Terech-Majewska E, Banaszkiewicz T. Effects of the herbicide Roundup on the ultrastructural pattern of hepatocytes in carp (Cyprinus carpio). Mar Environ Res. 2000;50:263-566.

Teh SJ, Adams SM, Hinton DE. Histopathologic biomarkers in feral freshwater fish populations exposed to different types of contaminant stress. Aquatic Toxicol. 1997;37:51-70.

Tierney KB, Baldwin DH, Hara TJ, Ross PS, Scholz NL, Kennedy CJ. Olfactory toxicity in fishes. Aquat Toxicol. 2010;96:2-26.

Tierney KB, Singh CR, Ross PS, Kennedy CJ. Relating olfactory neurotoxicity to altered olfactory-mediated behaviors in rainbow trout exposed to three currently-used pesticides. Aquat Toxicol. 2007;81:55-64.

Truta E, Vochita G, Rosu CM, Zamfirache MM, Olteanu Z. Evaluation of Roundup-induced toxicity on genetic material and on length growth of barley seedlings. Acta Biol Hung. 2011;62:290-301.

Tsui MT, Wang WX, Chu LM. Influence of glyphosate and its formulation (Roundup) on the toxicity and bioavailability of metals to Ceriodaphnia dubia. Environ Pollut. 2005;138:59-68.

Valdez Domingos FX, Azevedo M, Silva MD, Randi MAF, Freire CA, Silva De Assis HC, Oliveira Ribeiro CA. Multibiomarker assessment of three Brazilian estuaries using oysters as bioindicators. Environ Res. 2007;105:350-363.

Vallejo AN Jr, Ellis AE. Ultrastructural study of the response of eosinophil granule cells to Aeromonas salmonicida extracellular products and histamine liberators in rainbow trout Salmo gairdneri Richardson. Dev Comp Immunol. 1989;13:133-148.

Van Der Oost R, Beyer J, Vermeulen NPE. Fish bioaccumulation and biomarkers in environmental risk assessment: a review. Environ Toxicol Pharmacol. 2003;13:57-149.

Viarengo A, Lowe D, Bolognesi C, Fabbri E, Koehler A. The use of biomarkers in biomonitoring: A 2-tier approach assessing the level of pollutant-induced stress syndrome in sentinel organisms. Comp Biochem Physiol C Toxicol Pharmacol. 2007;146:281300.
Vieira CED, Almeida MDS, Galindo BA, Pereira L, Martinez CBDR. Integrated biomarker response index using a Neotropical fish to assess the water quality in agricultural areas. Neotrop Ichthyol. 2014;12:153-164.

Vigil JG, Ruiz MMDC, Anacabe DO. 2004. Solid herbicidal formulation of $n$-(phosphono-methyl)glycine and process for its preparation. United States patent application. US 2004/0102323 A1

Wang YS, Jaw CG, Chen YL. Accumulation of 2,4-D and glyphosate in fish and water hyacinth. Water Air Soil Pollut. 1994;74:397403.

Williams GM, Kroes R, Munro IC. Safety evaluation and risk assessment of the herbicide Roundup and its active ingredient, glyphosate, for humans. Regul Toxicol Pharmacol. 2000;31:117-165.

Williams RM, Bienenstock J, Stead RH. Mast cells: the neuroimmune connection. Chem Immunol. 1995;61:208-235.

Yin ZX, He W, Chen WJ, Yan JH, Yang JN, Chan SM, He JG. Cloning, expression and antimicrobial activity of an antimicrobial peptide, epinecidin-1, from the orange-spotted grouper, Epinephelus coioides. Aquaculture. 2006;253:204-211.

Zaccone G. Histochemical studies of epithelial mucosubstances, respiratory and pentose shunt enzymes in the skin epidermis of the air-breathing fish Mastacembelus erythrotaenia (Mastacembelidae, Pisces). Gegenbaurs Morphol Jahrb. 1982;128:918-931.

Zhou Q, Zhang J, Fu J, Shi J, Jiang G. Biomonitoring: an appealing tool for assessment of metal pollution in the aquatic ecosystem. Anal Chim Acta. 2008;606:135-150.

Zou J, Mercier C, Koussounadis A, Secombes C. Discovery of multiple beta-defensin like homologues in teleost fish. Mol Immunol. 2007; 44:638-647.

Zúñiga G. 2001. Sistemas de detección de daño genético, Universidad de Guadalajara.

Zupanc GKH. Neurogenesis and neuronal regeneration in the adult fish brain. J Comp Physiol A. 2006;192:649-670. 